\title{
Association of pre-pregnancy body mass index with adverse pregnancy outcome among first-time mothers
}

\author{
Li Li ${ }^{\text {Equal first author, 1, 2, } 3}$, Yanhong Chen ${ }^{\text {Equal first author, 2,4 }}{ }^{\text {, Zhifeng Lin }}{ }^{5}$, Weiyan Lin ${ }^{5}$, Yangqi Liu ${ }^{5}$, Weilin Ou ${ }^{5}$, Chengli Zeng ${ }^{5}$ \\ , Li Ke ${ }^{\text {Corresp. 2, 3, } 5}$ \\ ${ }^{1}$ Center for Reproductive Medicine, The Third Affiliated Hospital of Guangzhou Medical University, Guangzhou, Guangdong, China \\ 2 Key Laboratory for Major Obstetric Diseases of Guangdong Provinces, Guangzhou, Guangdong, China \\ 3 Key Laboratory of Reproduction and Genetics of Guangdong Higher Education Institutes, Guangzhou, Guangdong, China \\ 4 Department of Obstetrics and Gynecology, The Third Affiliated Hospital of Guangzhou Medical University, Guangzhou, Guangdong, China \\ 5 Department of Medical Record, The Third Affiliated Hospital of Guangzhou Medical University, Guangzhou, Guangdong, China \\ Corresponding Author: Li Ke \\ Email address: keli1221@126.com
}

Background: Studies have reported an increased risk of adverse pregnancy outcome associated with pre-pregnancy body mass index (BMI). However, the data on such associations in urban areas of southern Chinese women is limited, which drive us to clarify the associations of pre-pregnancy BMI and the risks of adverse pregnancy outcomes (preterm birth (PTB) and low birth weight (LBW)) and maternal health outcomes (gestational hypertension and cesarean delivery). Methods: We performed a hospitalbased case-control study including 3,864 Southern Chinese women who gave first birth to a live singleton infant from January 2015 to December 2015. PTB was stratified into three subgroups according to gestational age (extremely PTB, very PTB and moderate PTB). Besides, we combined birth weight and gestational age to dichotomise as being small for gestational age (SGA, less than the tenth percentile of weight for gestation) and non-small for gestational age (NSGA, large than the tenth percentile of weight for gestation), gestational week was also classified into categories of term, 34-36 week and below 34 week.. We then divided newborns into six groups: (1) term and NSGA; (2) 34-36 week gestation and NSGA; (3) below 34 week gestation and NSGA; (4) term and SAG; (5) 34-36 week gestation and SAG; (6) below 34 week gestation and SAG. Adjusted logistic regression models was used to estimate the odds ratios of adverse outcomes. Results: Underweight women were more likely to give LBW (AOR=1.44, 95\% $\mathrm{Cl} 1.11$ to 1.89), the similar result was seen in term and SAG as compare with term and NSAG (AOR=1.78, 95\% $\mathrm{Cl}$ 1.45-2.17). Whereas underweight was significantly associated with a lower risk of gestational hypertension ( $\mathrm{AOR}=0.45,95 \% \mathrm{Cl} 0.25-0.82$ ) and caesarean delivery $(\mathrm{AOR}=0.74,95 \% \mathrm{Cl} 0.62-0.90)$. The risk of extremely PTB is relatively higher among overweight and obese mothers in a subgroup analysis of PTB ( $\mathrm{AOR}=8.12,95 \% \mathrm{Cl}=1.11$ to 
59.44; $\mathrm{AOR}=15.06,95 \% \mathrm{Cl}=1.32$ to 172.13 , respectively). Both maternal overweight and obesity were associated with a greater risk of gestational hypertension (AOR=1.71, 95\% $\mathrm{Cl}=1.06$ to $2.77 ; \mathrm{AOR}=5.54,95 \% \mathrm{Cl}=3.02$ to 10.17 , respectively) and caesarean delivery $(\mathrm{AOR}=1.91,95 \% \mathrm{Cl}=1.53$ to $2.38 ; \mathrm{AOR}=1.85,95 \% \mathrm{Cl}=1.21$ to 2.82 , respectively).

Conclusions: Our study suggested that maternal overweight and obesity were associated with a significantly higher risk of gestational hypertension, caesarean delivery and extremely PTB. Underweight was correlated with an increased risk of LBW and conferred a protective effect regarding the risk for gestational hypertension and caesarean delivery for the first-time mothers among Southern Chinese. 


\section{Association of Pre-Pregnancy Body Mass Index with adverse pregnancy}

2 outcome among first-time mothers

3 Li Li ${ }^{1,2,3 *}$, Yanhong Chen ${ }^{2,4 *}$, Zhifeng Lin ${ }^{5}$, Weiyan Lin ${ }^{5}$, Yangqi Liu ${ }^{5}$, Weilin Ou${ }^{5}$, Chengli

4 Zeng, $\mathrm{Li} \mathrm{Ke}$

$5{ }^{1}$ Center for Reproductive Medicine, the Third Affiliated Hospital of Guangzhou Medical

6 University, Guangzhou, China

$7 \quad{ }^{2}$ Key Laboratory for Major Obstetric Diseases of Guangdong Provinces, Guangzhou, China

$8{ }^{3}$ Key Laboratory of Reproduction and Genetics of Guangdong Higher Education Institutes,

9 Guangzhou, China

$10{ }^{4}$ Department of Obstetrics and Gynecology, the Third Affiliated Hospital of Guangzhou Medical

11 University, Guangzhou, China

$12{ }^{5}$ Department of Medical Record, the Third Affiliated Hospital of Guangzhou Medical University,

13 Guangzhou, China

$15{ }^{*}$ These authors have contributed equally to this work

\section{\#Corresponding authors:}

17 Li Ke, Department of Medical Record, the Third Affiliated Hospital of Guangzhou Medical

18 University, Guangzhou 510310, China. Phone: 86-20-81292138; FAX: 86-20-81292908; E-mail:

19 keli1221@126.com. 
20

21

22

Abstract

Background: Studies have reported an increased risk of adverse pregnancy outcome associated with pre-pregnancy body mass index (BMI). However, the data on such associations in urban areas of southern Chinese women is limited, which drive us to clarify the associations of prepregnancy BMI and the risks of adverse pregnancy outcomes (preterm birth (PTB) and low birth weight (LBW)) and maternal health outcomes (gestational hypertension and cesarean delivery).

Methods: We performed a hospital-based case-control study including 3,864 Southern Chinese women who gave first birth to a live singleton infant from January 2015 to December 2015. PTB was stratified into three subgroups according to gestational age (extremely PTB, very PTB and moderate PTB). Besides, we combined birth weight and gestational age to dichotomise as being small for gestational age (SGA, less than the tenth percentile of weight for gestation) and nonsmall for gestational age (NSGA, large than the tenth percentile of weight for gestation), gestational week was also classified into categories of term, 34-36 week and below 34 week.. We then divided newborns into six groups: (1) term and NSGA; (2) 34-36 week gestation and NSGA; (3) below 34 week gestation and NSGA; (4) term and SAG; (5) 34-36 week gestation and SAG; (6) below 34 week gestation and SAG. Adjusted logistic regression models was used to estimate the odds ratios of adverse outcomes.

Results: Underweight women were more likely to give LBW (AOR=1.44, 95\% CI 1.11 to 1.89 ), the similar result was seen in term and SAG as compare with term and NSAG (AOR=1.78, 95\% CI 1.45-2.17). Whereas underweight was significantly associated with a lower risk of gestational hypertension $(\mathrm{AOR}=0.45,95 \% \mathrm{CI} 0.25-0.82)$ and caesarean delivery $(\mathrm{AOR}=0.74,95 \% \mathrm{CI} 0.62-$ 
41 0.90). The risk of extremely PTB is relatively higher among overweight and obese mothers in a 42 subgroup analysis of $\mathrm{PTB}(\mathrm{AOR}=8.12,95 \% \mathrm{CI}=1.11$ to $59.44 ; \mathrm{AOR}=15.06,95 \% \mathrm{CI}=1.32$ to

43172.13 , respectively). Both maternal overweight and obesity were associated with a greater risk 44 of gestational hypertension $(\mathrm{AOR}=1.71,95 \% \mathrm{CI}=1.06$ to $2.77 ; \mathrm{AOR}=5.54,95 \% \mathrm{CI}=3.02$ to 4510.17 , respectively) and caesarean delivery $(\mathrm{AOR}=1.91,95 \% \mathrm{CI}=1.53$ to $2.38 ; \mathrm{AOR}=1.85,95 \%$ $46 \mathrm{CI}=1.21$ to 2.82 , respectively).

47 Conclusions: Our study suggested that maternal overweight and obesity were associated with a 48 significantly higher risk of gestational hypertension, caesarean delivery and extremely PTB. 49 Underweight was correlated with an increased risk of LBW and conferred a protective effect 50 regarding the risk for gestational hypertension and caesarean delivery for the first-time mothers 51 among Southern Chinese.

52 Keyword: Pregnancy outcome; BMI; Preterm birth; Low birth weight; gestational hypertension; 53 caesarean delivery 


\section{Introduction}

55

Preterm birth (PTB) is an important adverse pregnancy outcome with a significant impact on infant mortality and morbidity (Boghossian et al. 2016). The incidence of PTB worldwide is expected to be $11.1 \%$, and China has more than 1.1 million PTB each year, which ranks second in the world (Blencowe et al. 2012). In spite of high-level advancement in healthcare services, the rate of PTB still seems to be climbing. According to statistics, perinatal mortality is as high as $70 \%$ in low birth weight (LBW) with neonatal weight below 2500 grams (Hack et al. 1994; Rutter 1995), most of them are born preterm. Growing evidence has shown that the incidence and development of PTB is a complex process that is influenced by a variety of environmental and genetic factors (He et al. 2017; Liu et al. 2017; Qiu et al. 2017; Xiao et al. 2016). Therefore, it is helpful to develop approaches of effective prevention and treatment of neonatal morbidity and mortality by elucidating etiological factors contributing to PTB or LBW.

Recent results provide support to pre-pregnancy maternal body mass index (BMI) is one of the potential risk factors for PTB (Hendler et al. 2005; Lynch et al. 2014; Shaw et al. 2014) and LBW (Han et al. 2011; Liu et al. 2016). In recent decades, the prevalence of obesity and overweight among women in many countries has increased at an alarming rate, especially in developing countries. Different countries, regions and incomes have different patterns of overweight and obesity that is more common among women in developing countries and men in developed countries ( $\mathrm{Ng}$ et al. 2014). Moreover, epidemiological studies have been suggested that maternal overweight and obesity have been shown to be association with PTB (Lynch et al. 2014; Shaw et al. 2014; Su et al. 2020), LBW (Rahman et al. 2015) and adverse maternal health 
75

outcomes, such as gestational hypertension (Santos et al. 2019) and cesarean delivery (Paidas Teefey et al. 2020; Rahman et al. 2015). Similarly, several observational studies show that underweight women in pre-pregnancy is the major risk factor for LBW and PTB (Ehrenberg et al. 2003; Madzia et al. 2020; Qu et al. 2019). However, the conclusions of various studies on the correlation between pre-pregnancy BMI and PTB appear to be paradoxical. It was reported that the risk of PTB in women with pre-pregnancy high BMI was significantly increased (Baeten et al. 2001; Chen et al. 2020; Cnattingius et al. 1998; Cnattingius et al. 2013; Weiss et al. 2004; Zhou et al. 2019), whereas other studies contradicted this result, suggesting that women with a high pre-pregnancy BMI could have a protective impact on PTB (Chen et al. 2013; Khashan \& Kenny 2009; Sebire et al. 2001). Furthermore, similar results have also been reported on association between pre-pregnancy BMI and LBW (Li et al. 2020; Ronnenberg et al. 2003a; Wu et al. 2020). However, there are relatively few studies of the effects of pre-pregnancy BMI on subsequent pregnancies for first-time mothers among Southern Chinese women. Although several researchers (Liu et al. 2019; Pan et al. 2016; Ronnenberg et al. 2003b) have conducted relevant research in domestic, these previous papers are mainly limited to earlier data or pregnant women in rural areas. Thus, studies on the role of pre-pregnancy BMI in adverse pregnancy outcomes for first-time mothers in urban areas of Southern China remain scarce.

Given above controversial results, we conducted a hospital-based case-control study to determine whether there is a higher risk of adverse outcome in women with abnormal BMI as compared with normal BMI women among first-time mothers in urban areas of southern China. 
96

97

98

99

100

101

102

103

104

105

106

107

108

109

110

111

112

113

114

115

116

\section{Methods}

\section{Study subjects}

8

This was a hospital-based, case-control study conducted in The Third Affiliated Hospital of Guangzhou Medical University, Guangdong, China. Pregnant women who gave birth for the first time were included between January 2015 and December 2015. A total of 322 women with PTB and 3,362 women with term delivery controls were enrolled. These people also could be divided into 317 cases of LBW and 3,367 controls of normal birth weight. This study was approved by the institutional review board of The Third Affiliated Hospital of Guangzhou Medical University, Guangdong, China (Medical Ethics Hearing [2020]No.036). And Institutional Review Board waived the need for consent.

The preterm group was defined to deliver within 37 weeks of conception without congenital abnormalities or neurological damage. The control group between 37 and 42 weeks of gestation without congenital abnormalities or neurological damage was matched with the case in the residential area for one week at the same hospital. For both groups, we excluded women with a multiple pregnancy, stillbirth, prior deliveries, embryo transfer and in vitro fertilization.

All data for this study was collected from women who gave their first birth during hospitalization, including maternal age, education, gravidity, occupation, health insurance, height and weight before of pregnancy. Gestational hypertension, caesarean delivery, birth weight and gestational week at delivery were obtained from the medical records. Pre-pregnancy BMI defined as the body weight in kilograms divided by the square of the height in metres $\left(\mathrm{kg} / \mathrm{m}^{2}\right)$. BMI is classified as underweight $\left(<18.5 \mathrm{~kg} / \mathrm{m}^{2}\right)$, normal weight $\left(18.5-23.9 \mathrm{~kg} / \mathrm{m}^{2}\right)$, overweight 
$117\left(24.0-27.9 \mathrm{~kg} / \mathrm{m}^{2}\right)$, and obesity $\left(\geqslant 28.0 \mathrm{~kg} / \mathrm{m}^{2}\right)$ according to the weight standard of Chinese 118 adults (Zhou \& Cooperative Meta-Analysis Group of the Working Group on Obesity in 2002). In 119 this study, child birth weight below 2500 grams was considered LBW. Once the two occasions 120 systolic blood pressure (BP) or diastolic BP values of pregnant women measured at intervals of 12124 hours exceed $140 \mathrm{mmHg}$ or $90 \mathrm{mmHg}$ respectively, they are diagnosed as gestational

122 123

124

125

126

127

128

129

130

131

132

133

134

135

136

137 hypertension.

\section{Statistical analysis}

$t$ test (for continuous variables) or $\chi 2$ test (for categorical variables) was used to assess the difference in demographic characteristics between two groups. Adjusted odds ratios (OR) with 95\% confidence intervals obtained from logistic regression model were used to quantify associations between pre-pregnancy BMI and adverse outcomes, adjusting for age, occupation, health insurance and education. We also further divided gestational age into four subtypes: extremely PTB (<28 gestational week), very PTB (28-31 gestational week), moderate PTB (32-

36 gestational week) and normal ( $\geqq 37$ gestational week). Besides, we referred to the method provided by Tanya Marchant et al (Marchant et al. 2012) apply to weight for gestational age, details were described as below: we combined birth weight and gestational age to dichotomise as being small for gestational age (SGA, less than the tenth percentile of weight for gestation) (Oken et al. 2003) and non-small for gestational age (NSGA, large than the tenth percentile of weight for gestation). As in previous studies, gestational week was classified into categories of term, 34-36 week and below 34 week. We then divided newborns into six groups: (1) term and 
138 NSGA; (2) 34-36 week gestation and NSGA; (3) below 34 week gestation and NSGA; (4) term 139 and SAG; (5) 34-36 week gestation and SAG; (6) below 34 week gestation and SAG. A two140 sided p-value of 0.05 or less was accepted to be statistically significant. Data were analyzed 141 using Statistical Analysis Software 9.4. (SAS Institute, Cary, NC). 
143

144

145

146

147

148

149

150

151

152

153

154

155

156

157

158

159

160

161

162

163

\section{Results}

\section{Characteristics of the study subjects}

The baseline maternal characteristics are shown in table 1 . Of the 3,684 live births, $8.7 \%$ $(n=322)$ were PTBs, and the remaining 91.3\% $(n=3362)$ were term births. The proportions of underweight, normal weight, overweight, and obesity women were $23.29 \%, 63.36 \%, 10.72 \%$, and $2.63 \%$, respectively. There were significant differences between PTB group and terms group with respect to age, health insurance, occupation and education (all $P<0.01$ ). There were no significant differences between the two groups with regard to gravidity $(P>0.05)$. The variables in the normal and the LBW group were basically the same as those in the term and preterm groups.

\section{Association analysis between pre-pregnancy BMI and adverse outcomes}

The association between pre-pregnancy BMI and the risk of adverse outcomes are considered in table 2 and table 3. Underweight, overweight and obesity did not increase the risk of PTB as compare with normal weight $(\mathrm{AOR}=1.01,95 \% \mathrm{CI}=0.76$ to 1.34 ; $\mathrm{AOR}=1.25,95 \%$ $\mathrm{CI}=0.87$ to 1.80 ; and $\mathrm{AOR}=1.27,95 \% \mathrm{CI}=0.65$ to 2.51 , respectively). However, When $\mathrm{PTB}$ was stratified into three subgroups, both maternal overweight and obesity increased the risks of extremely $\mathrm{PTB}(\mathrm{AOR}=8.12,95 \% \mathrm{CI}=1.11$ to $59.44 ; \mathrm{AOR}=15.06,95 \% \mathrm{CI}=1.32$ to 172.13 , respectively).

Pre-pregnancy underweight was significantly associated with the increased risk for LBW. In comparison with women who had normal pre-pregnancy BMI, women with low BMI category was more likely to deliver a $\mathrm{LBW}$ infant (crude $\mathrm{OR}=1.48,95 \% \mathrm{CI}=1.14$ to 1.93 ). After the 
164 adjustment for potential confounding factors, the AOR associated with the risk for giving birth to 165 a LBW infant were $1.44(95 \% \mathrm{CI}=1.11$ to 1.89$)$, the similar result was seen in table 4 as 166 compared with term and NSAG $(\mathrm{AOR}=1.78,95 \% \mathrm{CI}=1.45$ to 2.17$)$. Underweight was also 167 significantly associated with a lower risk of gestational hypertension ( $\mathrm{AOR}=0.45,95 \% \mathrm{CI}=0.25$ 168 to 0.82$)$ and caesarean delivery $(\mathrm{AOR}=0.74,95 \% \mathrm{CI}=0.62$ to 0.90$)$. Both maternal overweight 169 and obesity were found to be a risk factor for gestational hypertension $(\mathrm{AOR}=1.71,95 \% \mathrm{CI}=1.06$ 170 to 2.77 ; $\mathrm{AOR}=5.54,95 \% \mathrm{CI}=3.02$ to 10.17 , respectively $)$ and caesarean delivery $(\mathrm{AOR}=1.91,95 \%$ $171 \mathrm{CI}=1.53$ to $2.38 ; \mathrm{AOR}=1.85,95 \% \mathrm{CI}=1.21$ to 2.82 , respectively). 


\section{Discussion}

175 Our study demonstrated that maternal underweight prior to pregnancy, as compared with

176

177

178

normal weight women, significantly elevated the risk for LBW for the first-time mothers among

Southern Chinese. Maternal underweight were also found to be at lower risk of gestational hypertension and caesarean delivery. In women who had a high pre-pregnancy BMI, our study showed a significantly higher risk of gestational hypertension, caesarean delivery and extremely PTB.

The proportions of overweight and obesity were lower than underweight in our study, which were similar to previously reported data from other Chinese studies (Pan et al. 2016). Our finding showed that underweight women increase the risk of LBW in subsequent pregnancy, which is consistent with the result of a review study by Liu et al. (Liu et al. 2016). The study, including 60 studies covering 1,392,799 women, showed that infants had a higher risk of having a LBW when their mothers were underweight $(\mathrm{OR}, 1.67,95 \% \mathrm{CI}, 1.39-2.02)$ as compare to women with normal weight. Previous studies have demonstrated that maternal nutrition during pregnancy has great influence on providing the essential nutrients for fetal growth (Nnam 2015) and pregnant women who are undernourished tend to have LBW infant (Allen 2001). Maternal nutritional imbalance may be a key factor in the reduction of surface area and placental weight. In the lower surface area and placental weight, nutrient and waste transfer between the maternal and fetal circulation is reduced and other normal processes, such as fetal development and growth, are also restricted (Lechtig et al. 1975). Thus, maternal malnutrition may lead to LBW infant. Moreover, the finding in our study on association between underweight and LBW was also in line with 
195

196

197

198

199

200

201

202

203

204

205

206

207

208

209

210

211

212

213

215

214 However, conclusions on the relationship between pre-pregnancy BMI and PTB seem to be

previous literature (Li et al. 2013; Liu et al. 2012).

Previous literature has revealed that maternal overweight and obesity were associated with

the increased risk for gestational hypertension and caesarian delivery (Lewandowska et al. 2020;

Machado et al. 2020; Vince et al. 2020). Our study also confirmed these findings. However, the

risk of gestational hypertension and caesarean delivery were reduced among underweight

mothers. Although mechanism by which obesity responsible for the increased risk of gestational

hypertension or caesarean delivery is unclear, maternal obesity lead to an increase in the number

and size of adipocytes or pelvic malacia. A significant amount of adipocytes has been proposed

as a cause of excessive inflammatory reaction, pregnant female possibly experienced obstructive

dystocia due to pelvic malacia lead to a relatively narrow birth canal. Therefore, both gestational

hypertension and caesarean delivery were affected by obesity in obese mothers (Kriketos et al.

2004; Young \& Woodmansee 2002).

In our study, the risk of PTB is relatively higher among overweight and obese mothers but the association was not statistically significant (table 2). However, this association has dramatically changed in a subgroup analysis of gestational age (table 3). Our result regarding extremely PTB is consistent with a previous study (Su et al. 2020). Overweight and obesity are generally considered to be the risk factors for PTB due to the effects of placental insufficiency (Lassance et al. 2015; Pereira et al. 2015), inflammatory state (Gaillard et al. 2016), insulin sensitivity (Catalano et al. 1999) and cellular oxidative stress (Ballesteros-Guzman et al. 2019). paradoxical among different studies. The differences emerged between studies could be 
216 attributed to study design or power, recall bias, multiple comparisons, eating habits and different

217 ethnicities. Additionally, the category of BMI was different among the studies.

218 Although some confounding factors had been controlled, alcohol consumption and maternal

219 smoking were not adjusted as only one woman claimed to have a history of alcohol consumption

220 and smoking in our data. So we did not adjust for these two variables.

221 However, there are a number of potential limitations of this study that merit consideration.

222 One limitation of the current study is that it is difficult to distinguish between spontaneous and

223 iatrogenic PTB, which we could not assess the association between special types of PTB and pre-

224 pregnancy BMI. Additionally, the BMI we obtained in our study derived from weight and height

225 information by women self-reported, which could lead to bias risk estimates of PTB (Michels et

226 al. 1998).

227 In conclusion, our study suggested that maternal overweight and obesity were associated 228 with a significantly higher risk of gestational hypertension, caesarean delivery and extremely 229 PTB. Underweight was correlated with an increased risk of LBW and conferred a protective 230 effect regarding the risk for gestational hypertension and caesarean delivery for the first-time 231 mothers among Southern Chinese. 


\section{Acknowledgements}

234 The authors are grateful to all subjects who participated in this study.

235

236 Funding

237 The authors received no specific funding for this work.

238

239 Competing interests

240 The authors declare that they have no competing interests.

241

242

243

244

245

246

247

248

249

250

251

252

253

Peer) reviewing PDF | (2020:04:47383:2:0:NEW 10 Sep 2020) 
255

256

257

258

259

260

261

262

263

264

265

266

267

268

269

270

271

272

273

274

275

276

277

278

279

280

281

282

283

284

285

286

287

288

289

290

291

292

\section{References}

Allen LH. 2001. Biological mechanisms that might underlie iron's effects on fetal growth and preterm birth. $J$ Nutr 131:581S-589S.

Baeten JM, Bukusi EA, and Lambe M. 2001. Pregnancy complications and outcomes among overweight and obese nulliparous women. Am J Public Health 91:436-440.

Ballesteros-Guzman AK, Carrasco-Legleu CE, Levario-Carrillo M, Chavez-Corral DV, Sanchez-Ramirez B, Marinelarena-Carrillo EO, Guerrero-Salgado F, and Reza-Lopez SA. 2019. Prepregnancy Obesity, Maternal Dietary Intake, and Oxidative Stress Biomarkers in the Fetomaternal Unit. Biomed Res Int 2019:5070453.

Blencowe H, Cousens S, Oestergaard MZ, Chou D, Moller AB, Narwal R, Adler A, Vera Garcia C, Rohde S, Say L, and Lawn JE. 2012. National, regional, and worldwide estimates of preterm birth rates in the year 2010 with time trends since 1990 for selected countries: a systematic analysis and implications. Lancet 379:21622172.

Boghossian NS, McDonald SA, Bell EF, Carlo WA, Brumbaugh JE, Stoll BJ, Laptook AR, Shankaran S, Walsh MC, Das A, Higgins RD, Eunice Kennedy Shriver National Institute of Child H, and Human Development Neonatal Research N. 2016. Association of Antenatal Corticosteroids With Mortality, Morbidity, and Neurodevelopmental Outcomes in Extremely Preterm Multiple Gestation Infants. JAMA Pediatr 170:593601.

Catalano PM, Huston L, Amini SB, and Kalhan SC. 1999. Longitudinal changes in glucose metabolism during pregnancy in obese women with normal glucose tolerance and gestational diabetes mellitus. Am J Obstet Gynecol 180:903-916.

Chen CN, Chen HS, and Hsu HC. 2020. Maternal Prepregnancy Body Mass Index, Gestational Weight Gain, and Risk of Adverse Perinatal Outcomes in Taiwan: A Population-Based Birth Cohort Study. Int J Environ Res Public Health 17.

Chen Y, Li G, Ruan Y, Zou L, Wang X, and Zhang W. 2013. An epidemiological survey on low birth weight infants in China and analysis of outcomes of full-term low birth weight infants. BMC Pregnancy Childbirth 13:242.

Cnattingius S, Bergstrom R, Lipworth L, and Kramer MS. 1998. Prepregnancy weight and the risk of adverse pregnancy outcomes. N Engl J Med 338:147-152.

Cnattingius S, Villamor E, Johansson S, Edstedt Bonamy AK, Persson M, Wikstrom AK, and Granath F. 2013. Maternal obesity and risk of preterm delivery. JAMA 309:2362-2370.

Ehrenberg HM, Dierker L, Milluzzi C, and Mercer BM. 2003. Low maternal weight, failure to thrive in pregnancy, and adverse pregnancy outcomes. Am J Obstet Gynecol 189:1726-1730.

Gaillard R, Rifas-Shiman SL, Perng W, Oken E, and Gillman MW. 2016. Maternal inflammation during pregnancy and childhood adiposity. Obesity (Silver Spring) 24:1320-1327.

Hack M, Taylor HG, Klein N, Eiben R, Schatschneider C, and Mercuri-Minich N. 1994. School-age outcomes in children with birth weights under $750 \mathrm{~g}$. N Engl J Med 331:753-759.

Han Z, Mulla S, Beyene J, Liao G, McDonald SD, and Knowledge Synthesis G. 2011. Maternal underweight and the risk of preterm birth and low birth weight: a systematic review and meta-analyses. Int J Epidemiol 40:65101.

Peer) reviewing PDF | (2020:04:47383:2:0:NEW 10 Sep 2020) 
He JR, Lai YM, Liu HH, Liu GJ, Li WD, Fan XJ, Wei XL, Xia XY, Kuang YS, Liu XD, Chen NN, Lu JH, Chen QZ, Mai WB, Xia HM, and Qiu X. 2017. Maternal IGF1 and IGF1R polymorphisms and the risk of spontaneous preterm birth. J Clin Lab Anal 31.

Hendler I, Goldenberg RL, Mercer BM, lams JD, Meis PJ, Moawad AH, MacPherson CA, Caritis SN, Miodovnik M, Menard KM, Thurnau GR, and Sorokin Y. 2005. The Preterm Prediction Study: association between maternal body mass index and spontaneous and indicated preterm birth. Am J Obstet Gynecol 192:882886.

Khashan AS, and Kenny LC. 2009. The effects of maternal body mass index on pregnancy outcome. Eur J Epidemiol 24:697-705.

Kriketos AD, Greenfield JR, Peake PW, Furler SM, Denyer GS, Charlesworth JA, and Campbell LV. 2004. Inflammation, insulin resistance, and adiposity: a study of first-degree relatives of type 2 diabetic subjects. Diabetes Care 27:2033-2040.

Lassance L, Haghiac M, Leahy P, Basu S, Minium J, Zhou J, Reider M, Catalano PM, and Hauguel-de Mouzon S. 2015. Identification of early transcriptome signatures in placenta exposed to insulin and obesity. Am J Obstet Gynecol 212:647 e641-611.

Lechtig A, Yarbrough C, Delgado H, Martorell R, Klein RE, and Behar M. 1975. Effect of moderate maternal malnutrition on the placenta. Am J Obstet Gynecol 123:191-201.

Lewandowska M, Wieckowska B, and Sajdak S. 2020. Pre-Pregnancy Obesity, Excessive Gestational Weight Gain, and the Risk of Pregnancy-Induced Hypertension and Gestational Diabetes Mellitus. J Clin Med 9.

Li N, Liu E, Guo J, Pan L, Li B, Wang P, Liu J, Wang Y, Liu G, Baccarelli AA, Hou L, and Hu G. 2013. Maternal prepregnancy body mass index and gestational weight gain on pregnancy outcomes. PLoS One 8:e82310.

Li X, Gao R, Dai X, Liu H, Zhang J, Liu X, Si D, Deng T, and Xia W. 2020. The association between symptoms of depression during pregnancy and low birth weight: a prospective study. BMC Pregnancy Childbirth 20:147.

Liu GJ, He JR, Kuang YS, Fan XJ, Li WD, Lu JH, Xia XY, Liu XD, Chen NN, Mai WB, Xia HM, and Qiu X. 2017. Associations of maternal PLA2G4C and PLA2G4D polymorphisms with the risk of spontaneous preterm birth in a Chinese population. Mol Med Rep 15:3607-3614.

Liu L, Ma YN, Wang NN, Lin WJ, Liu Y, and Wen DL. 2019. Maternal body mass index and risk of neonatal adverse outcomes in China: a systematic review and meta-analysis. BMC Pregnancy Childbirth 19.

Liu P, Xu L, Wang Y, Zhang Y, Du Y, Sun Y, and Wang Z. 2016. Association between perinatal outcomes and maternal pre-pregnancy body mass index. Obes Rev 17:1091-1102.

Liu Y, Dai W, Dai X, and Li Z. 2012. Prepregnancy body mass index and gestational weight gain with the outcome of pregnancy: a 13-year study of 292,568 cases in China. Arch Gynecol Obstet 286:905-911.

Lynch AM, Hart JE, Agwu OC, Fisher BM, West NA, and Gibbs RS. 2014. Association of extremes of prepregnancy BMI with the clinical presentations of preterm birth. Am J Obstet Gynecol 210:428 e421-429.

Machado C, Monteiro S, Oliveira MJ, and Grupo de Estudo de Diabetes e Gravidez da Sociedade Portuguesa de D. 2020. Impact of overweight and obesity on pregnancy outcomes in women with gestational diabetes results from a retrospective multicenter study. Arch Endocrinol Metab 64:45-51.

Madzia J, McKinney D, Kelly E, and DeFranco E. 2020. Influence of Gestational Weight Gain on the Risk of Preterm Birth for Underweight Women Living in Food Deserts. Am J Perinatol.

Marchant T, Willey B, Katz J, Clarke S, Kariuki S, ter Kuile F, Lusingu J, Ndyomugyenyi R, Schmiegelow C, WatsonJones D, and Armstrong Schellenberg J. 2012. Neonatal mortality risk associated with preterm birth in East 
Africa, adjusted by weight for gestational age: individual participant level meta-analysis. PLoS Med 9:e1001292.

Michels KB, Greenland S, and Rosner BA. 1998. Does body mass index adequately capture the relation of body composition and body size to health outcomes? Am J Epidemiol 147:167-172.

Ng M, Fleming T, Robinson M, Thomson B, Graetz N, Margono C, Mullany EC, Biryukov S, Abbafati C, Abera SF, Abraham JP, Abu-Rmeileh NM, Achoki T, AlBuhairan FS, Alemu ZA, Alfonso R, Ali MK, Ali R, Guzman NA, Ammar W, Anwari P, Banerjee A, Barquera S, Basu S, Bennett DA, Bhutta Z, Blore J, Cabral N, Nonato IC, Chang JC, Chowdhury R, Courville KJ, Criqui MH, Cundiff DK, Dabhadkar KC, Dandona L, Davis A, Dayama A, Dharmaratne SD, Ding EL, Durrani AM, Esteghamati A, Farzadfar F, Fay DF, Feigin VL, Flaxman A, Forouzanfar MH, Goto A, Green MA, Gupta R, Hafezi-Nejad N, Hankey GJ, Harewood HC, Havmoeller R, Hay S, Hernandez L, Husseini A, Idrisov BT, Ikeda N, Islami F, Jahangir E, Jassal SK, Jee SH, Jeffreys M, Jonas JB, Kabagambe EK, Khalifa SE, Kengne AP, Khader YS, Khang YH, Kim D, Kimokoti RW, Kinge JM, Kokubo Y, Kosen S, Kwan G, Lai T, Leinsalu M, Li Y, Liang X, Liu S, Logroscino G, Lotufo PA, Lu Y, Ma J, Mainoo NK, Mensah GA, Merriman TR, Mokdad AH, Moschandreas J, Naghavi M, Naheed A, Nand D, Narayan KM, Nelson EL, Neuhouser ML, Nisar MI, Ohkubo T, Oti SO, Pedroza A, Prabhakaran D, Roy N, Sampson U, Seo H, Sepanlou SG, Shibuya K, Shiri R, Shiue I, Singh GM, Singh JA, Skirbekk V, Stapelberg NJ, Sturua L, Sykes BL, Tobias M, Tran BX, Trasande L, Toyoshima H, van de Vijver S, Vasankari TJ, Veerman JL, VelasquezMelendez G, Vlassov VV, Vollset SE, Vos T, Wang C, Wang X, Weiderpass E, Werdecker A, Wright IL, Yang YC, Yatsuya H, Yoon J, Yoon SJ, Zhao Y, Zhou M, Zhu S, Lopez AD, Murray CJ, and Gakidou E. 2014. Global, regional, and national prevalence of overweight and obesity in children and adults during 1980-2013: a systematic analysis for the Global Burden of Disease Study 2013. Lancet 384:766-781.

Nnam NM. 2015. Improving maternal nutrition for better pregnancy outcomes. Proc Nutr Soc 74:454-459.

Oken E, Kleinman KP, Rich-Edwards J, and Gillman MW. 2003. A nearly continuous measure of birth weight for gestational age using a United States national reference. BMC Pediatr 3:6.

Paidas Teefey C, Reforma L, Koelper NC, Sammel MD, Srinivas SK, Levine LD, and Durnwald CP. 2020. Risk Factors Associated With Cesarean Delivery After Induction of Labor in Women With Class III Obesity. Obstet Gynecol 135:542-549.

Pan Y, Zhang S, Wang Q, Shen H, Zhang Y, Li Y, Yan D, and Sun L. 2016. Investigating the association between prepregnancy body mass index and adverse pregnancy outcomes: a large cohort study of 536098 Chinese pregnant women in rural China. BMJ Open 6:e011227.

Pereira RD, De Long NE, Wang RC, Yazdi FT, Holloway AC, and Raha S. 2015. Angiogenesis in the placenta: the role of reactive oxygen species signaling. Biomed Res Int 2015:814543.

Qiu X, Gao F, Qiu Y, Bao J, Gu X, Long Y, Liu F, Cai M, and Liu H. 2017. Association of maternal serum homocysteine concentration levels in late stage of pregnancy with preterm births: a nested case-control study. J Matern Fetal Neonatal Med:1-5.

Qu P, Liu F, Zhao D, Wang Y, Wang M, Wang L, Dang S, Wang D, Shi J, and Shi W. 2019. A propensity-matched study of the association between pre-pregnancy maternal underweight and perinatal outcomes of singletons conceived through assisted reproductive technology. Reprod Biomed Online 39:674-684.

Rahman MM, Abe SK, Kanda M, Narita S, Rahman MS, Bilano V, Ota E, Gilmour S, and Shibuya K. 2015. Maternal body mass index and risk of birth and maternal health outcomes in low- and middle-income countries: a systematic review and meta-analysis. Obes Rev 16:758-770. 
Ronnenberg AG, Wang X, Xing H, Chen C, Chen D, Guang W, Guang A, Wang L, Ryan L, and Xu X. 2003a. Low preconception body mass index is associated with birth outcome in a prospective cohort of Chinese women. Journal of Nutrition 133:3449-3455.

Ronnenberg AG, Wang XB, Xing HX, Chen CZ, Chen DF, Guang WW, Guang AQ, Wang LH, Ryan L, and Xu XP. 2003b. Low preconception body mass index is associated with birth outcome in a prospective cohort of Chinese women. Journal of Nutrition 133:3449-3455.

Rutter N. 1995. The extremely preterm infant. Br J Obstet Gynaecol 102:682-687.

Santos S, Voerman E, Amiano P, Barros H, Beilin L, Bergstrom A, Charles MA, Chatzi L, Chevrier C, Chrousos GP, Corpeleijn E, Costa O, Costet N, Crozier S, Devereux G, Doyon M, Eggesbo M, Fantini MP, Farchi S, Forastiere F, Georgiu V, Godfrey KM, Gori D, Grote V, Hanke W, Hertz-Picciotto I, Heude B, Hivert MF, Hryhorczuk D, Huang RC, Inskip H, Karvonen AM, Kenny LC, Koletzko B, Kupers LK, Lagstrom H, Lehmann I, Magnus P, Majewska R, Makela J, Manios Y, McAuliffe FM, McDonald SW, Mehegan J, Melen E, Mommers M, Morgen CS, Moschonis G, Murray D, Ni Chaoimh C, Nohr EA, Nybo Andersen AM, Oken E, Oostvogels A, Pac A, Papadopoulou E, Pekkanen J, Pizzi C, Polanska K, Porta D, Richiardi L, Rifas-Shiman SL, Roeleveld N, Ronfani L, Santos AC, Standl M, Stigum H, Stoltenberg C, Thiering E, Thijs C, Torrent M, Tough SC, Trnovec T, Turner S, van Gelder M, van Rossem L, von Berg A, Vrijheid M, Vrijkotte T, West J, Wijga AH, Wright J, Zvinchuk O, Sorensen T, Lawlor DA, Gaillard R, and Jaddoe V. 2019. Impact of maternal body mass index and gestational weight gain on pregnancy complications: an individual participant data meta-analysis of European, North American and Australian cohorts. BJOG 126:984-995.

Sebire NJ, Jolly M, Harris JP, Wadsworth J, Joffe M, Beard RW, Regan L, and Robinson S. 2001. Maternal obesity and pregnancy outcome: a study of 287,213 pregnancies in London. Int J Obes Relat Metab Disord 25:1175-1182.

Shaw GM, Wise PH, Mayo J, Carmichael SL, Ley C, Lyell DJ, Shachar BZ, Melsop K, Phibbs CS, Stevenson DK, Parsonnet J, Gould JB, and March of Dimes Prematurity Research Center at Stanford University School of M. 2014. Maternal prepregnancy body mass index and risk of spontaneous preterm birth. Paediatr Perinat Epidemiol 28:302-311.

Su XJ, Huang SJ, Li X, and Du QL. 2020. Prepregnancy Overweight and Obesity Are Associated with an Increased Risk of Preterm Birth in Chinese Women. Obes Facts 13:237-244.

Vince K, Brkic M, Poljicanin T, and Matijevic R. 2020. Prevalence and impact of pre-pregnancy body mass index on pregnancy outcome: a cross-sectional study in Croatia. J Obstet Gynaecol:1-5.

Weiss JL, Malone FD, Emig D, Ball RH, Nyberg DA, Comstock CH, Saade G, Eddleman K, Carter SM, Craigo SD, Carr SR, D'Alton ME, and Consortium FR. 2004. Obesity, obstetric complications and cesarean delivery rate--a population-based screening study. Am J Obstet Gynecol 190:1091-1097.

Wu J, Yang X, Huang J, Kuang Y, Chen Q, and Wang Y. 2020. Effect of maternal body mass index on neonatal outcomes in women with endometriosis undergoing IVF. Reprod Biomed Online 40:559-567.

Xiao Q, Cui YY, Lu J, Zhang GZ, and Zeng FL. 2016. Risk for Gestational Diabetes Mellitus and Adverse Birth Outcomes in Chinese Women with Polycystic Ovary Syndrome. Int J Endocrinol 2016:5787104.

Young TK, and Woodmansee B. 2002. Factors that are associated with cesarean delivery in a large private practice: the importance of prepregnancy body mass index and weight gain. Am J Obstet Gynecol 187:312-318; discussion 318-320.

Zhou BF, and Cooperative Meta-Analysis Group of the Working Group on Obesity in C. 2002. Predictive values of 
416

417

418

419

420

421

422 body mass index and waist circumference for risk factors of certain related diseases in Chinese adults-study on optimal cut-off points of body mass index and waist circumference in Chinese adults. Biomed Environ Sci 15:83-96.

Zhou Y, Li H, Zhang Y, Zhang L, Liu J, and Liu J. 2019. Association of Maternal Obesity in Early Pregnancy with Adverse Pregnancy Outcomes: A Chinese Prospective Cohort Analysis. Obesity (Silver Spring) 27:10301036. 


\section{Table $\mathbf{1}$ (on next page)}

Baseline maternal characteristics of the first-time mothers between two groups

Table 1 
1 Table 1:

2 Baseline maternal characteristics of the first-time mothers between two groups

\begin{tabular}{|c|c|c|c|c|c|c|}
\hline variable & Terms $(\mathrm{N}=3362)$ & PTB $(\mathrm{N}=322)$ & $P$ & Normal $(\mathrm{N}=3367)$ & LBW (N=317) & $P$ \\
\hline Age & & & $<0.001$ & & & $<0.001$ \\
\hline$<25$ & $421(12.52)$ & $55(17.08)$ & & $418(12.41)$ & $58(18.30)$ & \\
\hline $25-34$ & $2628(78.17)$ & $220(68.32)$ & & $2630(78.11)$ & $218(68.77)$ & \\
\hline$\geqq 35$ & $313(9.31)$ & $47(14.60)$ & & $319(9.48)$ & $41(12.93)$ & \\
\hline Health insurance & & & $<0.001$ & & & $<0.001$ \\
\hline Care for urban employees & $2269(67.49)$ & $161(50.00)$ & & $2261(67.15)$ & $169(53.31)$ & \\
\hline Free medical service & $87(2.59)$ & $6(1.86)$ & & $90(2.67)$ & $3(0.95)$ & \\
\hline Full-cost & $1006(29.92)$ & $155(47.14)$ & & $1016(30.18)$ & $145(45.74)$ & \\
\hline Occupation & & & 0.004 & & & 0.007 \\
\hline Professional & $1534(45.63)$ & $119(36.96)$ & & $1532(45.50)$ & $121(38.17)$ & \\
\hline Business & $355(10.56)$ & $28(8.70)$ & & $358(10.63)$ & $25(7.89)$ & \\
\hline Housewife & $389(11.57)$ & $46(14.29)$ & & $388(11.52)$ & $47(14.83)$ & \\
\hline Others & $1084(32.24)$ & $129(40.06)$ & & $1089(32.35)$ & $124(39.12)$ & \\
\hline Gravidity & & & 0.214 & & & 0.875 \\
\hline$<2$ & $2245(66.78)$ & $204(63.35)$ & & $2237(66.44)$ & $212(66.88)$ & \\
\hline$\geqq 2$ & $1117(33.22)$ & $118(36.65)$ & & $1130(33.56)$ & $105(33.12)$ & \\
\hline Education & & & $<0.001$ & & & $<0.001$ \\
\hline Less than high school & $439(13.06)$ & $86(26.71)$ & & $444(13.19)$ & $81(25.55)$ & \\
\hline High school & $444(13.21)$ & $38(11.80)$ & & $443(13.16)$ & $39(12.30)$ & \\
\hline College & $2479(73.73)$ & $198(61.49)$ & & $2480(73.65)$ & $197(62.15)$ & \\
\hline
\end{tabular}

3 Abbreviation: PTB, preterm birth; LBW, low birth weight. 


\section{Table 2 (on next page)}

Crude and AOR for the association between pre-pregnancy BMI and adverse outcomes

Table 2 
2 Crude and AOR for the association between pre-pregnancy BMI and adverse outcomes

\begin{tabular}{|c|c|c|c|c|c|c|c|}
\hline Outcomes & BMI status & Case & Control & OR $(95 \% \mathrm{CI})$ & $P$ & $\mathrm{AOR}^{*}(95 \% \mathrm{CI})$ & $P$ \\
\hline \multirow[t]{4}{*}{ PTB } & Underweight & $\begin{array}{c}75(23.29) \\
197\end{array}$ & $\begin{array}{c}783 \\
(23.29) \\
2137\end{array}$ & $\begin{array}{c}1.04(0.79- \\
1.37) \\
1.00\end{array}$ & 0.787 & $1.01(0.76-1.34)$ & 0.943 \\
\hline & Normal weight & $(61.18)$ & $(63.56)$ & $\begin{array}{l}\text { (reference) } \\
1.22(0.86-\end{array}$ & & 1.00 (reference) & \\
\hline & Overweight & $40(12.42)$ & $355(10.56)$ & $\begin{array}{c}1.75) \\
125(064-\end{array}$ & 0.272 & $1.25(0.87-1.80)$ & 0.224 \\
\hline & Obesity & $10(3.11)$ & $87(2.59)$ & $\begin{array}{l}2.44) \\
18\end{array}$ & 0.519 & $1.27(0.65-2.51)$ & 0.486 \\
\hline \multirow[t]{4}{*}{ LBW } & Underweight & $94(29.65)$ & 764 (22.69) & 1.93) & 0.003 & 1.44 (1.11-1.89) & 0.007 \\
\hline & Normal weight & $\begin{array}{c}179 \\
(56.47)\end{array}$ & $\begin{array}{c}2155 \\
(64.00)\end{array}$ & $\begin{array}{c}1.00 \\
\text { (reference) } \\
1.13(0.77-\end{array}$ & & 1.00 (reference) & \\
\hline & Overweight & $34(10.73)$ & $361(10.73)$ & $\begin{array}{c}1.66) \\
1.38(0.71-\end{array}$ & 0.521 & $1.17(0.80-1.73)$ & 0.423 \\
\hline & Obesity & $10(3.15)$ & $87(2.58)$ & $\begin{array}{c}2.71) \\
0.43(0.24-\end{array}$ & 0.343 & $1.41(0.72-2.78)$ & 0.322 \\
\hline \multirow[t]{4}{*}{ Gestational hypertension } & Underweight & $13(9.92)$ & $\begin{array}{c}845(23.78) \\
2254\end{array}$ & $\begin{array}{c}\text { 0.78) } \\
1.00\end{array}$ & 0.006 & $0.45(0.25-0.82)$ & 0.009 \\
\hline & Normal weight & $80(61.07)$ & $(63.44)$ & $\begin{array}{l}\text { (reference) } \\
1.74 \text { (1.08- }\end{array}$ & & 1.00 (reference) & \\
\hline & Overweight & $23(17.56)$ & $372(10.47)$ & $\begin{array}{c}2.81) \\
5.15(2.85\end{array}$ & 0.022 & $1.71(1.06-2.77)$ & $\mathbf{0 . 0 3}$ \\
\hline & Obesity & $\begin{array}{c}15(11.45) \\
194\end{array}$ & $82(2.31)$ & $\begin{array}{c}9.33) \\
0.70(0.59\end{array}$ & $<0.001$ & $5.54(3.02-10.17)$ & $<0.001$ \\
\hline \multirow[t]{3}{*}{ Cesarean delivery } & Underweight & $\begin{array}{c}(17.60) \\
686\end{array}$ & $\begin{array}{c}664(25.72) \\
1684\end{array}$ & $\begin{array}{c}\mathbf{0 . 8 4}) \\
1.00\end{array}$ & $<0.001$ & $0.74(0.62-0.90)$ & 0.002 \\
\hline & Normal weight & $\begin{array}{c}(62.25) \\
180\end{array}$ & $(63.83)$ & $\begin{array}{l}\text { (reference) } \\
\mathbf{2 . 0 1}(\mathbf{1 . 6 2}-\end{array}$ & & 1.00 (reference) & \\
\hline & Overweight & (16.33) & $215(8.33)$ & $2.50)$ & $<0.001$ & $1.91(1.53-2.38)$ & $<0.001$ \\
\hline
\end{tabular}


$4{ }^{*}$ Adjusted OR and 95\% CI were calculated by the logistic regression model after adjusting for age, health insurance, occupation and education. 


\section{Table 3(on next page)}

Adjusted $^{*}$ a relative risk for the associations between pre-pregnancy BMI and PTB by gestational age

Table 3 
1 Table 3:

2 Adjusted* a relative risk for the associations between pre-pregnancy BMI and PTB by gestational age

\begin{tabular}{lcccc}
\hline Gestational age & Underweight & Normal weight & Overweight & Obesity \\
\hline Term & - & 1.00 (reference) & - & - \\
Moderately PTB & $0.97(0.71-1.33)$ & 1.00 (reference) & $1.18(0.79-1.77)$ & $1.23(0.58-2.59)$ \\
Very PTB & $1.05(0.54-2.02)$ & 1.00 (reference) & $1.28(0.55-2.96)$ & $0.77(0.10-5.77)$ \\
Extremely PTB & $3.22(0.53-19.59)$ & 1.00 (reference) & $\mathbf{8 . 1 2 ( 1 . 1 1 - 5 9 . 4 4 )}$ & $\mathbf{1 5 . 0 6 ( 1 . 3 2 - 1 7 2 . 1 3 )}$
\end{tabular}

3 Abbreviations: PTB, preterm birth.

4 *Adjusted OR and 95\% CI were calculated by the logistic regression model after adjusting for age, health insurance, occupation and education. 


\section{Table 4 (on next page)}

Adjusted* a relative risk for the associations between pre-pregnancy BMI and weight for gestational age

\section{Table 4}


1 Table 4:

2 Adjusted* a relative risk for the associations between pre-pregnancy BMI and weight for gestational age

\begin{tabular}{|c|c|c|c|c|}
\hline Weight for gestational age & Underweight & Normal weight & Overweight & Obesity \\
\hline \multicolumn{5}{|l|}{ NSAG } \\
\hline Term & - & 1.00 (reference) & - & - \\
\hline 34-36 week & $0.88(0.58-1.34)$ & 1.00 (reference) & $1.29(0.80-2.06)$ & $1.40(0.59-3.29)$ \\
\hline$<34$ week & $1.52(0.94-2.47)$ & 1.00 (reference) & $1.48(0.77-2.84)$ & $0.97(0.23-4.11)$ \\
\hline \multicolumn{5}{|l|}{$\mathrm{SAG}$} \\
\hline Term & $1.78(1.45-2.17)$ & 1.00 (reference) & $0.88(0.63-1.21)$ & $1.89(0.48-1.66)$ \\
\hline 34-36 week & $1.49(0.79-2.81)$ & 1.00 (reference) & $0.43(0.10-1.82)$ & $0.86(0.12-6.41)$ \\
\hline$<34$ week & $0.73(0.20-2.63)$ & 1.00 (reference) & $1.62(0.44-5.89)$ & $2.23(0.28-17.91)$ \\
\hline
\end{tabular}

3 Abbreviations: NSAG, non-small for gestational age; SAG, small for gestational age.

$4{ }^{*}$ Adjusted OR and 95\% CI were calculated by the logistic regression model after adjusting for age, health insurance, occupation and education. 